\title{
Aetiology of Urinary Outflow Obstruction at a tertiary Care Hospital in Bangladesh
}

\author{
Jahangir Alam ${ }^{1}$, Rumi Farhad Ara ${ }^{2}$, Din Mohammad ${ }^{3}$, Abdul Quddus ${ }^{4}$ \\ ${ }^{1}$ Associate Professor, Department of Surgery, Shaheed Suhrawardy Medical College, Dhaka, Bangladesh; ${ }^{2}$ Associate Professor, \\ Department of Gynaecology \& Obstetrics, Kushtia Medical College, Kushtia, Bangladesh; ${ }^{3}$ Associate Professor, Department of \\ Surgery, Shaheed Suhrawardy Medical College, Dhaka, Bangladesh; ${ }^{4}$ Professor, Department of Surgery, TMSS Medical College, \\ Bogra, Bangladesh
}

[Reviewed: 30 August 2017; Accepted on: 1 November 2017; Published on: 1 January 2018]

\section{Abstract}

Background: There are several etiologies of urinary tract obstructions. Objective: The purpose of the present study was to find out the etiology of urinary tract obstructions. Methodology: This cross-sectional study was conducted in the Department of Surgery at Rajshahi Medical College, Rajshahi, Bangladesh from September 1994 to December 1995 for a period of one year and three months. All the patients who were presented with bladder outflow obstruction and were admitted in the general surgical unit of the hospital were taken as study population. Result: A total number of 50 patients were recruited for this study. The most frequent cause of bladder outflow obstruction was benign enlargement of prostate (26.0\%), next common cause was impacted urethra stone (22.0\%) and stricture urethra (22.0\%). Rupture urethra was found in $7(14.0 \%)$ cases and carcinoma of prostate was found in 3(6.0\%) cases. Conclusion: In conclusion the most frequent cause of bladder outflow obstruction is benign enlargement of prostate, impacted urethra stone and stricture urethra. [Journal of Current and Advance Medical Research 2018;5(1):3-6]

Keywords: Aetiologies; urinary tract obstructions; infection

Correspondence: Dr. Jahangir Alam, Associate Professor, Department of Surgery, Shaheed Suhrawardy Medical College, SherE-Bangla Nagar, Dhaka, Bangladesh; Email: jahangirdr11@gmail.com; Cell no.: +8801711480495

Cite this article as: Alam J, Ara RF, Mohammad D, Quddus A. Aetiology of Urinary Outflow Obstruction at a tertiary Care Hospital in Bangladesh. Journal of Current and Advance Medical Research 2018;5(1):3-6

Conflict of Interest: All the authors have declared that there was no conflict of interest.

Contributions to authors: Alam J has contributed in protocol preparation up to surgical procedures as well as the report writing; furthermore, Ara RF, Mohammad D and Quddus A have written the manuscript and have revised the manuscript.

Copyright: (2)18 Alam et al. Published by Journal of Current and Advance Medical Research. This article is published under the Creative Commons CC BY-NC License (https://creativecommons.org/licenses/by-nc/4.0/). This license permits use, distribution and reproduction in any medium, provided the original work is properly cited, and is not used for commercial purposes.

\section{Introduction}

When considering the causes of bladder outlet obstruction (BOO), it is important to appreciate that BOO results from a variety of etiologies, which may be functional or anatomic ${ }^{1}$. BOO often produces lower urinary tract symptoms (LUTS), although the degree of bother by LUTS is highly variable and not predictable on the basis of the specific inciting etiology ${ }^{2}$. Induced LUTS symptoms may be predominantly obstructive, irritative, or often a combination of both. Typically, obstructive symptoms include hesitancy, sensation of incomplete bladder emptying, diminished urinary stream, and post voiding urinary dribbling. Irritative complaints include urinary urgency, frequency of urination, occasional dysuria, and nocturia ${ }^{3-4}$.

Rarely are symptoms related to BOO isolated; often the individual experiencing LUTS presents with a 
variety of mixed symptoms of obstruction and irritation. BOO may also occur in the complete absence of symptoms and be first identified in the scenario of urinary retention or decompensation of the upper urinary tracts 5 .

Urinary bladder outflow obstruction is considered as one of the extreme catastrophe in comparison to other surgical emergencies ${ }^{1}$. Obstruction is one of the most important abnormalities of the urinary tract, since it eventually leads to decomposition of the muscular conduits and reservoirs, back pressure, and atrophy of renal parenchyma. It also invites infection and stone formation, which cause additional damage and can ultimately end in complete unilateral or bilateral destruction of the kidneys ${ }^{2}$.

There are numerous etiological factors associated with urinary outflow obstruction which are frequently encountered in day to day practice ${ }^{3}$. Among them benign enlargement of the prostate, carcinoma prostate, urethral stone, stricture urethra, rupture urethra, bladder neck obstruction, meatal ulcer with scabbing are seems to be commonest pathological events ${ }^{4}$. The present study was aimed to find out the aetiology of urinary tract obstructions.

\section{Methodology}

This study was designed as cross sectional study of 30 patients with bladder outflow obstruction. All of these patients were admitted in the general surgical unit of Rajshahi Medical College Hospital from the period of September 1994 to December 1995 for a period of one year and four months. All the patients who were presented with bladder outflow obstruction and were admitted in the general surgical unit of the hospital were taken as study population. The details etiologies were recorded after taking consent to enroll in this study.

\section{Results}

A total number of 50 patients were recruited for this study. The age of the patients was ranged from 2 to 70 years. The age range was 41 to 50 years. Majority of the study population were in the age group of 40 to 50 years which was $11(22.0 \%)$ cases followed by 51 to 60 years and 0 to 10 years which were $9(18.0 \%)$ cases in each group. Furthermore 21 to 30 years and 61 to 70 years old age group were in $8(16.0 \%)$ cases in each group. However, 31 to 40 years was in $3(6.0 \%)$ cases. In 11 to 20 year age group only $2(4.0 \%)$ cases were recorded (Table 1$)$.
Table 1: Age Distribution among the Study Population $(\mathbf{n}=\mathbf{5 0})$

\begin{tabular}{|l|c|c|}
\hline Age Group & Frequency & Percentage \\
\hline 0 to 10 Years & 9 & 18.0 \\
\hline 11 to 20 Years & 2 & 4.0 \\
\hline 21 to 30 Years & 8 & 16.0 \\
\hline 31 to 40 Years & 3 & 6.0 \\
\hline 41 to 50 Years & 11 & 22.0 \\
\hline 51 to 60 Years & 9 & 18.0 \\
\hline 61 to 70 Years & 8 & 16.0 \\
\hline Total & $\mathbf{5 0}$ & $\mathbf{1 0 0 . 0}$ \\
\hline
\end{tabular}

Male were overwhelming majority which was $96.0 \%$ and female was constituted only $4.0 \%$. The male and female ratio was 24:1 (Table 2).

Table 2: Sex distribution of patients $(n=50)$

\begin{tabular}{|l|c|c|}
\hline Sex & Frequency & Percentage \\
\hline Male & 48 & 96.0 \\
\hline Female & 2 & 4.0 \\
\hline Total & $\mathbf{5 0}$ & $\mathbf{1 0 0 . 0}$ \\
\hline
\end{tabular}

The most frequent cause of bladder outflow obstruction was benign enlargement of prostate (26.0\%), next common cause was impacted urethra stone $(22.0 \%)$ and stricture urethra $(22.0 \%)$. However the rupture urethra was found in $7(14.0 \%)$ cases; carcinoma of prostate was in $3(6.0 \%)$ cases and neurogenic bladder and urinary bladder neoplasm were in $2(4.0 \%$ ) cases in each (Table 3 ).

Table 3: Relative incidence of different diseases for bladder outflow obstruction $(n=50)$

\begin{tabular}{|l|c|c|}
\hline Disease & Frequency & Percentage \\
\hline $\begin{array}{l}\text { Benign enlargement } \\
\text { prostate }\end{array}$ & 13 & 26.0 \\
\hline Impacted urethral stone & 11 & 22.0 \\
\hline Stricture urethra & 11 & 22.0 \\
\hline Rupture urethra & 7 & 14.0 \\
\hline Carcinoma Prostate & 3 & 6.0 \\
\hline Neurogenic bladder & 2 & 4.0 \\
\hline $\begin{array}{l}\text { Urinary bladder } \\
\text { neoplasm }\end{array}$ & 2 & 4.0 \\
\hline Posterior urethral valve & 1 & 2.0 \\
\hline Total & $\mathbf{5 0}$ & $\mathbf{1 0 0 . 0}$ \\
\hline
\end{tabular}

\section{Discussion}

Management and presentation of bladder outlet obstruction has under marked changes in the last 50 years. More experience, new techniques of surgery. Understanding of urinary bladder pathology and path physiology, modern scientific instrument, greatly improved the overall management ${ }^{5}$. But, still bladder outflow obstruction surgical problem. 
The present study was done in Rajshahi Medical College Hospital, Rajshahi, Bangladesh, over a period of September 1994 to December 1995. This is one of the divisional medical college hospitals in this country where specialized urology unit is lacking and Mariology patients are managed in nasal surgical unit. Rajshahi Medical College Hospital is the biggest hospital in the northern side of Bangladesh. Therefore, the present study reflects pattern of urological problems in the zone. Fifty cases studied in this series included bladder outlet obstruction admitted in general surgical unit.

The age of the patients in this series ranged from 2 to 70 years. The peak incidence was 41 to 50 years; the age group which were commonly involved are 0 to 10 years $(9.0 \%), 21$ to 30 years $(16 \%)$ and 41 above $(56 \%)$. In the present series, $96.0 \%$ patients were male with male to female ratio of 24:1. Bladder outlet obstruction was less occurred in the female and it was due to the fact that in this series only surgical patients were included. Bladder outflow obstruction due to benign prostatic hyperplasia is a common problem in elderly men and by the age of 80 years most men have developed symptoms attributable to this disorder. The symptoms may be either obstructive or irritative in type. Less common causes of bladder outflow obstruction are bladder neck obstruction and urethral stricture.

The etiology of BOO is diverse and definitely gender specific ${ }^{7}$. Often anatomic causes induce functional abnormality that remains somewhat unique for each individual, regardless of sex. A full appreciation of the possible etiologies of obstruction is necessary in order to identify overt and more subtle scenarios. In women, iatrogenic causes of obstruction are the most common. Other entities account for far fewer of the cases. The obstruction evaluation in women is somewhat more diverse in terms of modalities used, with no single grouping of techniques that are generally apropos. Individualized evaluation remains a tenet of analysis, and urodynamic criteria used to diagnose BOO in women continue to evolve ${ }^{8}$. In men, by far the most common entity producing $\mathrm{BOO}$ is $\mathrm{BPO} / \mathrm{BPE}$. Again, symptomatic appraisal is a crucial component of evaluation in order to assess the magnitude of symptom impact. The combination of PVR, urinary flow measures, and symptom appraisal has been generally accepted as the initial screening and evaluation paradigm for BOO and LUTS in men and are now considered standard ${ }^{10}$. More complex techniques such as voiding pressure flow studies remain the gold standard and are more thoroughly standardized in men than in women.
Causes of bladder outlet obstruction were excluded from this series. In this series; benign enlargement of prostate was the common cause of the bladder outlet obstructions reported. Bladder outlet obstructions due to benign hyperplasia foretaste which is a common problem in elderly men, and by the age of 80 years, most men have developed symptom attributable to this factors. Majority of benign enlarged prostate in this series about 70 years of age but in another series, it was 80 years ${ }^{11}$. The aetiology of the irritative symptoms is poorly understood. Obstruction of the urethra by an enlarged prostate leads to a poor urinary flow. The bladder may take longer to generate a high enough pressure to start the flow of urine, and this pressure may not be sustained over the (prolonged) voiding cycle.

This leads to hesitancy and intermittency. Other causes of irritative symptoms which merit attention are bladder cancer, urinary tract infection, urethral stricture, bladder diverticula, bladder calculus, and neuropathic bladder dysfunction ${ }^{5,9}$.

\section{Conclusion}

In conclusion benign enlargement of prostate is the most frequent cause of bladder outflow obstruction followed by impacted urethra stone and stricture urethra. Rupture urethra and carcinoma of prostate are also found as cause of urinary outflow obstructions. Further large scale study should be conducted as multicentre basis so that the result will represent the whole country scenario.

\section{References}

1. Speakman MJ, Brading AF, Gilpin CJ, Dixon JS, Gilpin SA, Gosling JA. Bladder outflow obstruction--a cause of denervation supersensitivity. The Journal of urology. 1987;138(6):1461-6

2. Athanasopoulos A, Gyftopoulos K, Giannitsas K, Fisfis J, Perimenis P, Barbalias G. Combination treatment with an $\alpha$-blocker plus an anticholinergic for bladder outlet obstruction: a prospective, randomized, controlled study. The Journal of urology. 2003;169(6):2253-6.

3. Blaivas JG, Groutz A. Bladder outlet obstruction nomogram for women with lower urinary tract symptomatology. Neurourology and Urodynamics. 2000;19(5):553-64.

4. Nitti VW, Le Mai T, Gitlin J. Diagnosing bladder outlet obstruction in women. The Journal of urology. 1999;161(5):1535-40.

5. Groutz A, Blaivas JG, Chaikin DC. Bladder outlet obstruction in women: definition and characteristics. Neurourology and urodynamics. 2000;19(3):213-20.

6. Manieri C, Carter SS, Romano G, Trucchi A, Valenti M, Tubaro A. The diagnosis of bladder outlet obstruction in men by ultrasound measurement of bladder wall thickness. The Journal of urology. 1998;159(3):761-5. 
7. Katakwar P, Thakur R. Clinical study and management of bladder outlet obstruction. International Surgery Journal. 2017;4(4):1272-5.

8. Nagarathnam M, Latheef SA. Prevalence of lower urinary tract symptoms in patients of benign prostatic hyperplasia attending Tertiary Care Hospital in the State of Andhra Pradesh. Journal of Dr. NTR University of Health Sciences. 2017;6(3):154

9. Abrams P, Kaplan S, Gans HJ, Millard R. Safety and tolerability of tolterodine for the treatment of overactive bladder in men with bladder outlet obstruction. The Journal of urology. 2006;175(3):999-1004

10. Blaivas JG, Groutz A. Bladder outlet obstruction nomogram for women with lower urinary tract symptomatology. Neurourology and urodynamics. 2000;19(5):553-64

11. Groutz A, Blaivas JG, Chaikin DC. Bladder outlet obstruction in women: definition and characteristics. Neurourology and Urodynamics. 2000;19(3):213-20 